\title{
Effect of temporomandibular joint articular disc repositioning on anterior open-bite malocclusion: An orthodontic-surgical approach
}

\author{
Jonas Bianchi, Ary dos Santos Pinto, Jaqueline Ignácio, Daniel Patrick Obelenis Ryan, \\ and João Roberto Gonçalves \\ Araraquara, São Paulo, Brazil
}

\begin{abstract}
An anterior open bite is a challenge to orthodontic treatment; it has a multifactorial etiology and a wide range of intervention options. Temporomandibular joint (TMJ) disorders are a risk factor for the development of malocclusions such as the anterior open bite, especially in patients who have TMJ osteoarthritis with disc displacement. Articular disc repositioning surgery is an available option for treating this pathology, and it contributes to maintaining the condyles in a more stable position. The aim of this article was to report the case of a 20-year-old woman diagnosed with anterior open bite and TMJ osteoarthritis with bilateral disc displacement. The patient received both orthodontic treatment and TMJ disc repositioning surgery. Cone-beam computed tomography was used to create 3-dimensional models of the condyles with regional superposition, and assessment of bone remodeling was performed at different time intervals. Complete orthodontic and surgical treatment time was approximately 12 months. The results provided a stable correction of the patient's anterior open bite with a 2-year follow-up and favorable bone remodeling of the condyles due to functional improvement of the TMJ. (Am J Orthod Dentofacial Orthop 2017;152:848-58)
\end{abstract}

\begin{abstract}
A $n$ anterior open bite $(A O B)$ is a deviation of the normal vertical relationship of the maxillary and mandibular arches. As with most orthodontic problems, its etiology is multifactorial, involving hereditary and environmental factors. ${ }^{1,2}$ Clinical characteristics include excessive gonial, mandibular, and occlusal plane angles; small mandibular body and ramus; increased lower anterior facial height; decreased upper anterior facial height; Class II tendency; and inadequate lip coverage. $^{3}$ The hyperdivergent pattern associated with prolonged sucking habits is also a significant risk factor. ${ }^{4}$ It is necessary to distinguish between dental and skeletal open bites; as a diagnosis of dentoalveolar open bite, it is usually associated with harmful habits or trauma.

From the Department of Pediatric Dentistry, Araraquara Dental School, Paulista State University, Araraquara, São Paulo, Brazil.

All authors have completed and submitted the 1CMJE Form for Disclosure of Potential Conflicts of Interest, and none were reported.

Address correspondence to: Jonas Bianchi, Department of Pediatric Dentistry, Araraquara Dental School, Rua Humaita, 1680, Centro, CEP: 14801-903, Araraquara, São Paulo, Brazil; e-mail, jonasbianchi.unesp@gmail.com.

Submitted, June 2016; revised and accepted, September 2016.

$0889-5406 / \$ 36.00$

(C) 2017 by the American Association of Orthodontists. All rights reserved.

http://dx.doi.org/10.1016/j.ajodo.2016.09.032
\end{abstract}

However, when there is a skeletal component, other tissues are also frequently involved such as lymphatic vessel hypertrophy, muscular hypotonicity, allergic responses, airway obstruction, disproportionate tongue, harmful tongue habits, temporomandibular joint (TMJ) derangements, and others. ${ }^{5,6}$

Treatment of AOB includes habit control, orthodontic treatment associated with 4 premolar extractions, posterior tooth intrusion with miniplates (skeletal anchorage system), and surgical procedures. The best treatment option to correct an AOB and provide a better quality of life to the patient depends on the etiology of the problem. Furthermore, it has been shown that many conditions of the TMJ may be related to this type of malocclusion..$^{7-9}$ The most common disorders are articular disc displacement, adolescent internal condylar resorption, reactive arthritis, condylar hyperplasia, autoimmune diseases, osteoarthritis, and advanced reactive arthritis. $^{10,11}$ TMJ osteoarthritis is noteworthy because of its involvement with occlusal development, craniofacial growth, and long-term stability. ${ }^{12-14}$ A common complication of this disease is condylar resorption, which can lead to an anteriorly displaced disc and an AOB. This condition requires a 

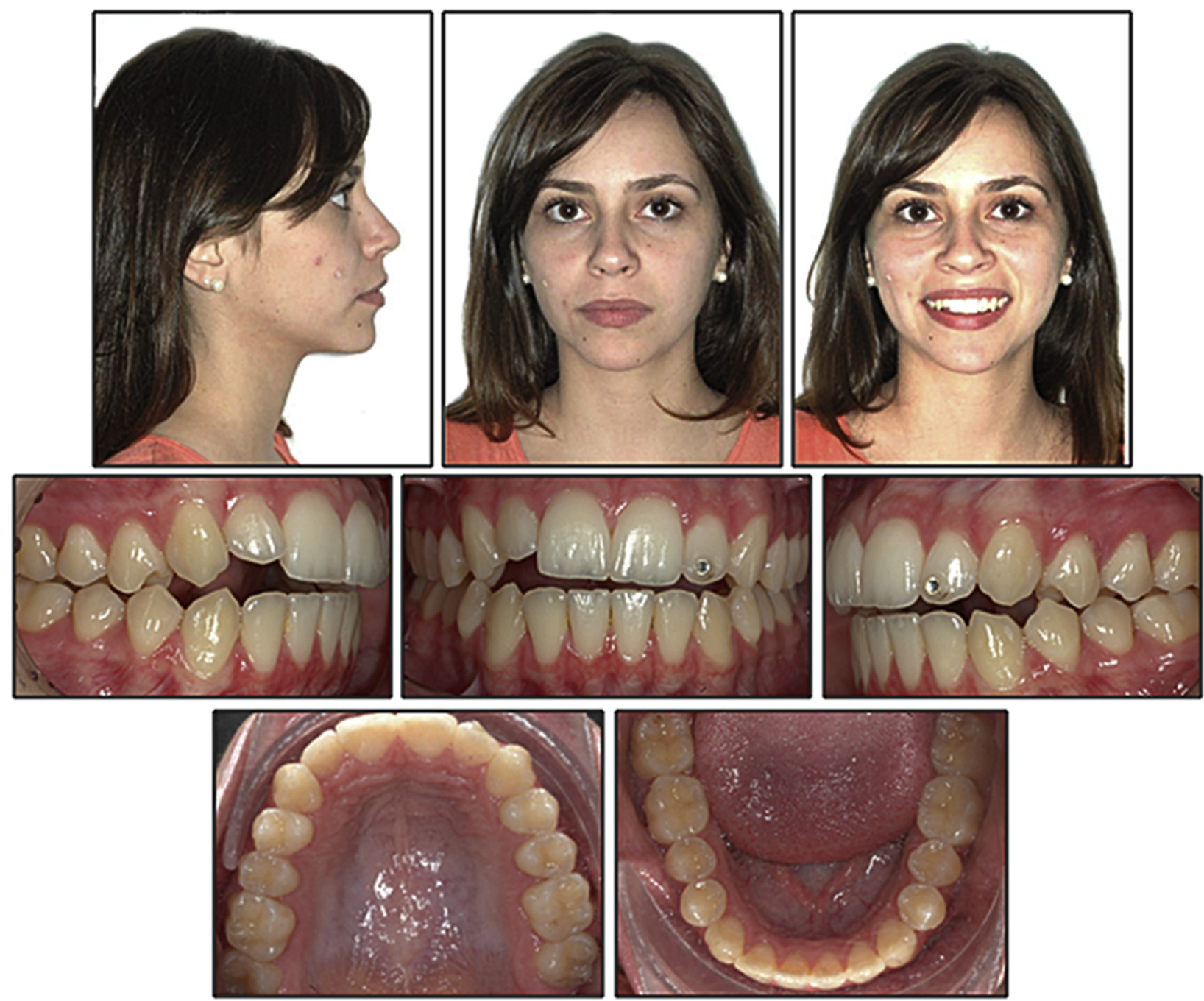

Fig 1. Pretreatment facial and intraoral photos.

combined therapeutic approach, including surgical and orthodontic interventions. Moreover, the advantages of using 3-dimensional (3D) images as a tool allow the clinician to get a better understanding of the information from examinations such as cone-beam computed tomography (CBCT). In this case report, we explored an $\mathrm{AOB}$ malocclusion treatment that benefited from articular disc repositioning surgery.

\section{DIAGNOSIS AND ETIOLOGY}

A 20-year-old woman had a slight mandibular retrusion and a Class 1 dental malocclusion, mainly associated with her AOB, which extended to the posterior teeth (Fig 1). Her skeletal pattern was vertical, and the maxillary and mandibular incisor inclinations determined the convexity of the lips within adequate parameters for her ethnic

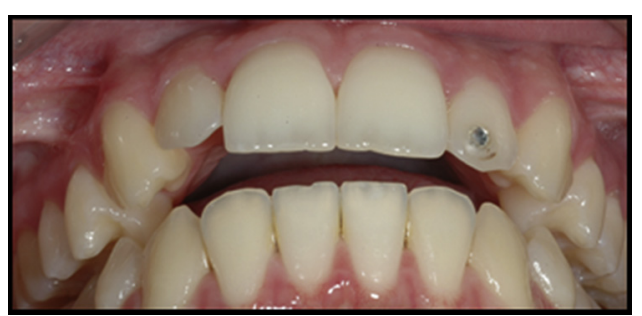

Fig 2. Occlusal relationship at pretreatment.

background. Her main complaints were the dental esthetics altered by the AOB, the deficient occlusion of the posterior teeth with interference of the maxillary molar palatal cusps over the mandibular molar buccal ones (Fig 2), and severe orofacial pain with episodes of migraine since her childhood. 

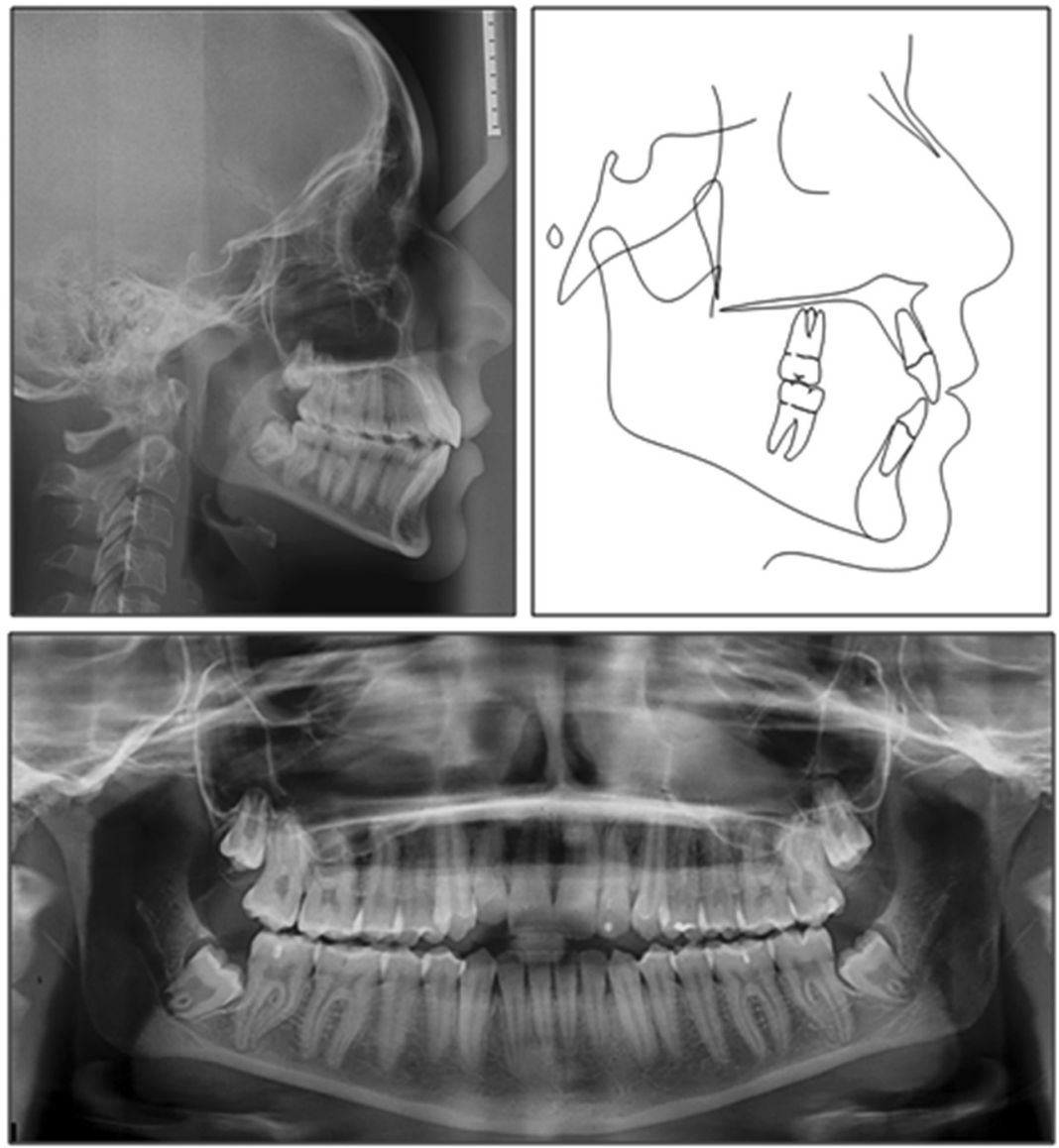

Fig 3. Pretreatment lateral cephalogram, panoramic radiograph, and cephalometric tracing.
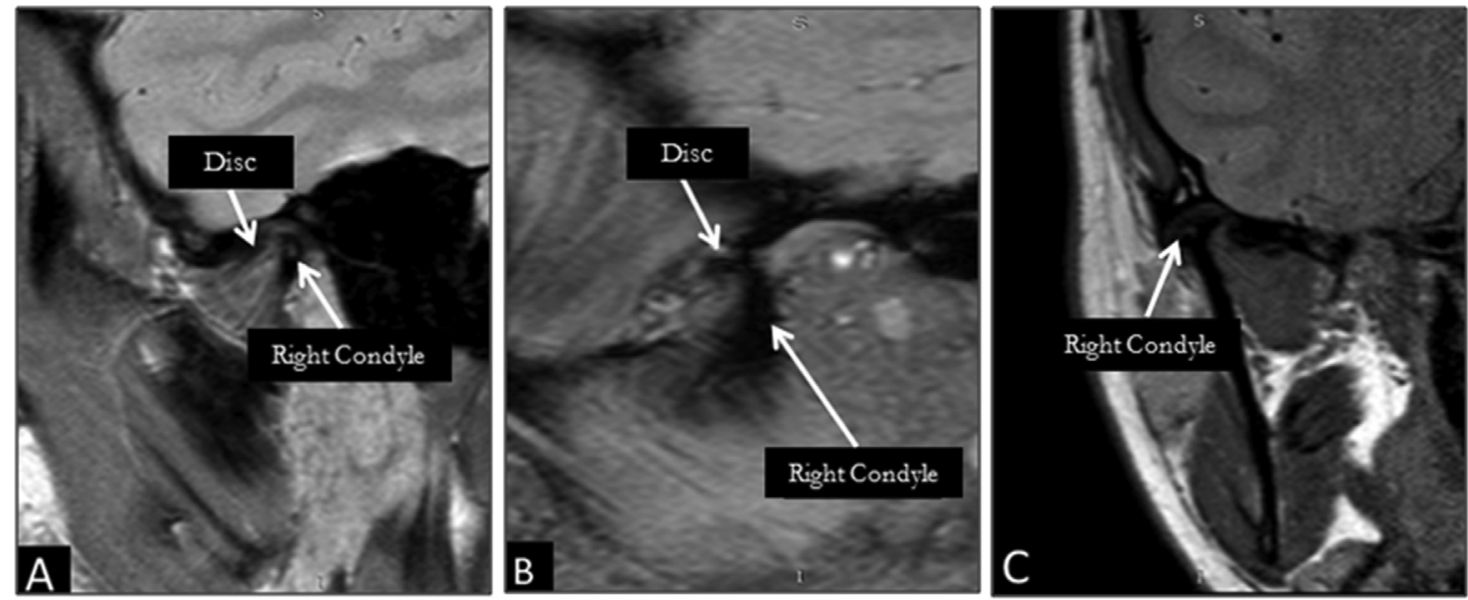

Fig 4. Proton density weighted $\mathrm{MRI}$ of the right TMJ shows the mandibular condyle with irregular contours, flattening of the articular surface, and anterior osteophytes. There is marked condylar resorption with a low-intensity signal in the medullar bone. A, Closed-mouth view shows that the disc is anteriorly displaced, with irregular signal and heterogeneous format; $\mathbf{B}$, open-mouth view shows nonreducible disc; $\mathbf{C}$, coronal view shows marked reduction of the medullar bone. 

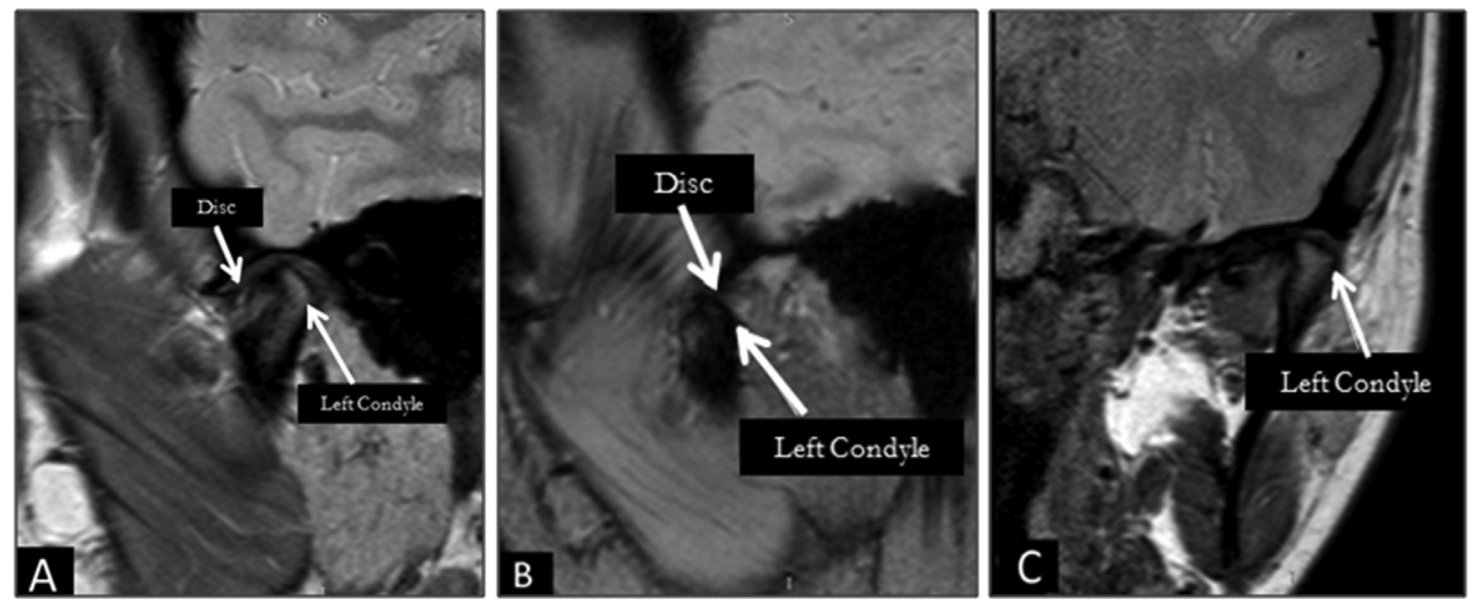

Fig 5. Proton density weighted MRI of the left TMJ shows the mandibular condyle with posterior surface flattening with a homogeneous high-intensity medullar bone signal. A, Disc is anteriorly displaced on closed-mouth sagittal view; $\mathbf{B}$, on total mouth opening, the disc is in normal position; $\mathbf{C}$, the coronal view shows that medullar bone is preserved with homogeneous hypersignal.
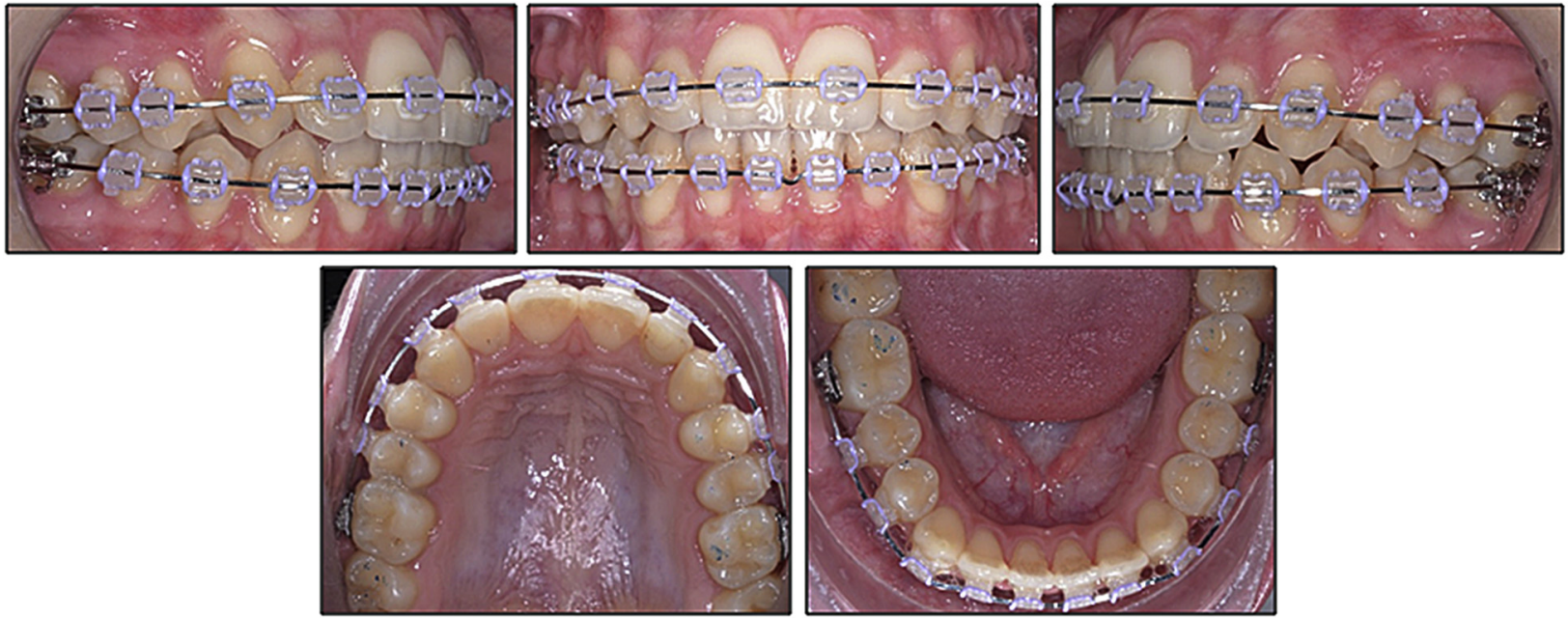

Fig 6. Intraoral photographs 7 months after TMJ disc repositioning showing a better anterior occlusal relationship with decreased $A O B$.

Radiographic examination showed bilateral condylar remodeling (more pronounced on the right side), third molar impactions, narrow symphysis, and AOB (Fig 3). Muscular and articular temporomandibular disorder became apparent during the physical examination, with the right side the most affected. We also noticed bilateral TMJ clicking with deviation of the mandible to the right side on opening. Osteoarthritis was also considered as a diagnosis. Magnetic resonance imaging (MRI) and $\mathrm{CBCT}$ examinations of the TMJs were required to confirm the hypothesis. The MRI showed reduced mandibular condyles, increased cortical range, and signs of degeneration in the joint discs, with more pronounced degeneration on the right TMJ. The left disc had anterior displacement with reduction, and the right TMJ disc had anterior displacement without reduction (Figs 4 and 5). The 3D models of the condyles before treatment were generated from the CBCT files using3D SLICER (SPHARM-PMD) ${ }^{15}$ and ITK-SNAP software. ${ }^{16}$ The 3D models showed areas with condylar flatness, cortical irregularities, and osteophytes that can be visualized in the online Supplementary Material (Supplementary 3D Models, available at www.ajodo. 

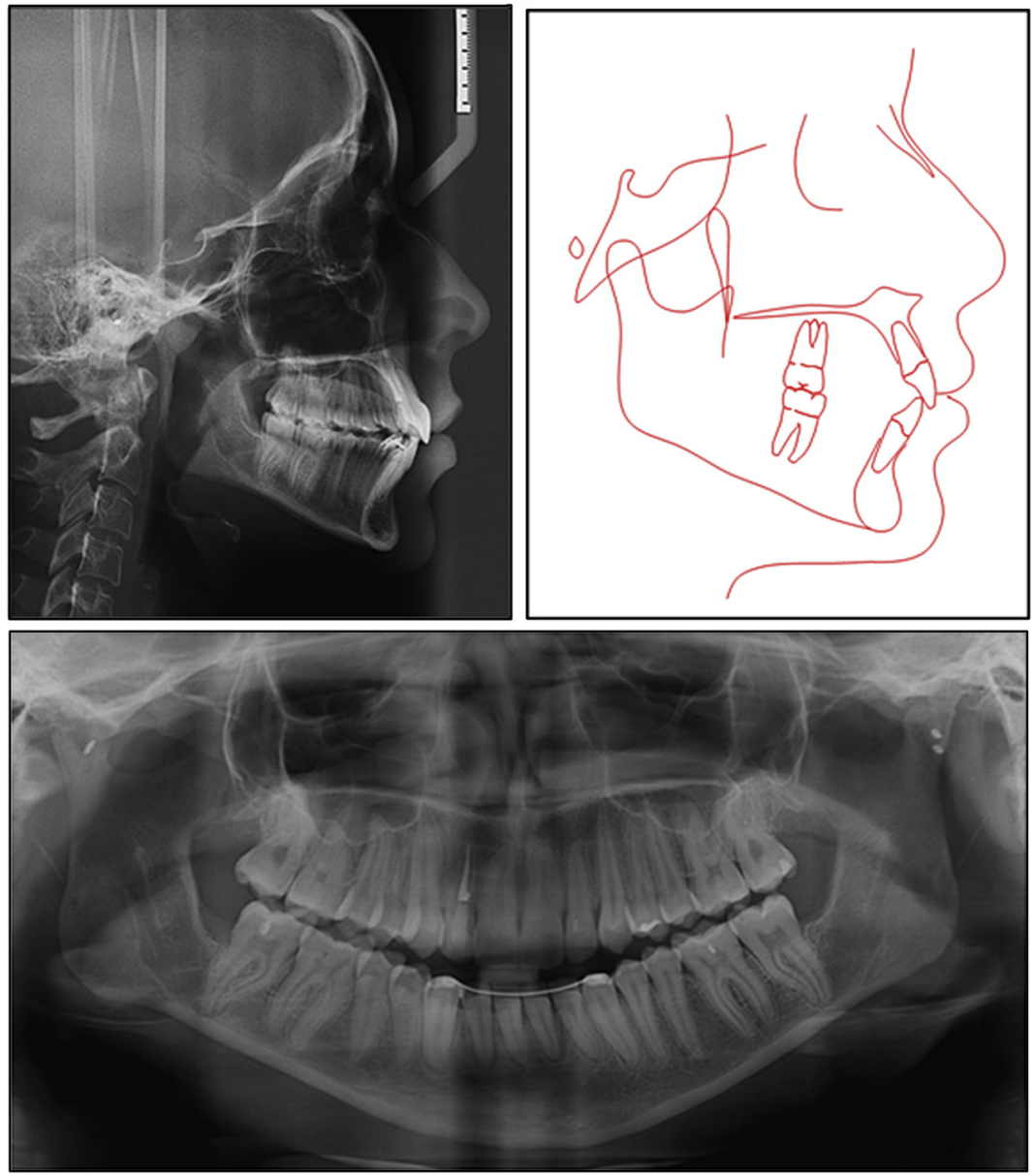

Fig 7. Posttreatment lateral cephalogram, panoramic radiograph, and cephalometric tracing (immediately after treatment).

org). These symptoms confirmed the hypothesis of osteoarthritis, which was more advanced on the right side.

\section{TREATMENT OBJECTIVES}

The treatment objectives were to improve the dentofacial esthetics, maintain a dental Class I malocclusion, correct the $\mathrm{AOB}$, minimize TMJ pain, and improve function.

\section{TREATMENT ALTERNATIVES}

An AOB malocclusion has several etiologic possibilities, and the treatment is a challenge in orthodontics. The patient must first be correctly diagnosed so that stability can be maintained after the treatment. ${ }^{4,5,17,18}$ Interventions in skeletal AOB differ from growing to nongrowing patients. In growing patients, the reduction of the vertical skeletal growth with intraoral or extraoral force is the main treatment objective. In nongrowing patients, the treatment objective is to correct the dentoalveolar position with camouflage or surgical intervention. ${ }^{18}$ Extrusion of the anterior segment with elastics, retraction and vertical repositioning of the maxillary and mandibular anterior teeth by extraction of the premolars, and intrusion of the posterior teeth are also strategies used to treat skeletal $\mathrm{AOB}$ in nongrowing patients. ${ }^{18-21}$ Orthognathic surgery is indicated when the $\mathrm{AOB}$ is associated with skeletal discrepancies. ${ }^{17}$

AOB, reduced overbite, and increased overjet are known to be associated with internal derangement of the TMJ and TMJ osteoarthritis. ${ }^{14,22-24}$ When condylar resorption is bilateral, the mandible rotates posteriorly and frequently presents as a skeletal Class 11 malocclusion with AOB. ${ }^{25}$ Many treatment options are described in the literature. In general, patients primarily undergo nonsurgical treatments, such as physiotherapy, occlusal splint therapy, and medication to relieve 


\begin{tabular}{|c|c|c|}
\hline & Initial & Final \\
\hline SNA $\left({ }^{\circ}\right)$ & 78.9 & 78.2 \\
\hline $\operatorname{SNB}\left({ }^{\circ}\right)$ & 74.5 & 73.5 \\
\hline $\operatorname{ANB}\left({ }^{\circ}\right)$ & 4.4 & 4.8 \\
\hline U1 to NA (mm) & 2.8 & 3.2 \\
\hline $\mathrm{U} 1$ to $\mathrm{SN}\left({ }^{\circ}\right)$ & 94.3 & 96.7 \\
\hline $\mathrm{L} 1$ to $\mathrm{NB}(\mathrm{mm})$ & 6.1 & 6.8 \\
\hline $\mathrm{L} 1$ to mandibular plane (MP) $\left({ }^{\circ}\right)$ & 98.6 & 98.7 \\
\hline MP to SN $\left({ }^{\circ}\right)$ & 40 & 38.9 \\
\hline
\end{tabular}

functional limitation and pain. ${ }^{26,27}$ After initial conservative treatment, orthodontics and surgery become options, such as intrusion of the maxillary molars with miniscrews or miniplates, maxillary or mandibular surgery for occlusal deformity correction, gradual mandibular advancement with distraction osteogenesis, and TMJ interventions followed, or not, by orthognathic surgery. ${ }^{25,28-32}$

An alternative is to combine the orthodontic treatment with the use of a splint. After the initial splinting therapy, orthodontic treatment is conducted for occlusal reconstruction at the splint-induced condylar position. Both archwires (maxillary and mandibular) are used simultaneously with the splint and vertical elastics to prevent anterior intrusion. Afterward, the splint is reduced in size gradually according to the orthodontic progress. ${ }^{33}$ However, if a pathologic condition such as osteoarthritis with TMJ disc displacement is not treated, the long-term prognosis of this condition may allow a new progression of condylar resorption, occlusal relapse, and TMJ pain. ${ }^{28-31}$

Our patient was eager to improve her facial and dental appearance and minimize the TMJ pain. Thus, the clinical approach consisted of surgical and orthodontic treatment that included bilateral TMJ articular disc repositioning surgery and fixed orthodontic appliances.

\section{TREATMENT PROGRESS}

Initial leveling and alignment of the maxillary dental arch was achieved with 0.016-in nickel-titanium thermal archwire, using the straight-wire technique and Roth prescription 0.022-in slot braces. The patient had requested rheumatoid, endocrine, and gynecologic screening. The results were negative for autoimmune disease and any other pathology. After 18 days, bilateral TMJ articular disc repositioning surgery and extraction of all 4 third molars were performed. It was noticed during the TMJ surgery that there was a high adherence of the disc on the right side with signals of degenerative

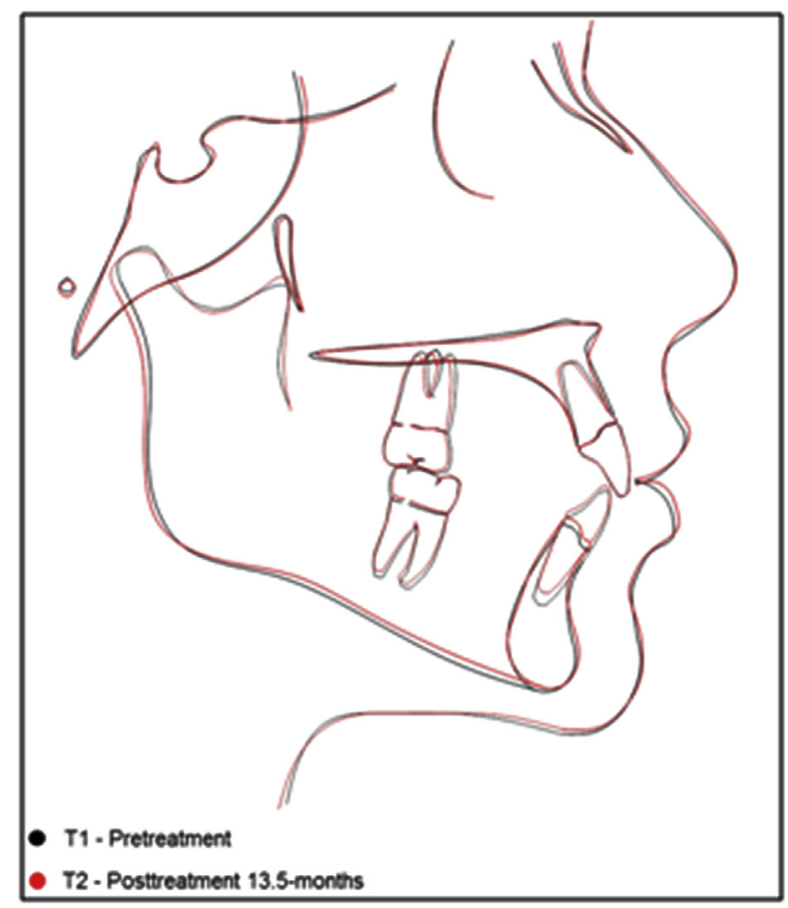

Fig 8. Pretreatment and posttreatment lateral cephalometric tracing superimpositions on the cranial base.

joint disease. Fourteen days later, alignment and leveling of the mandibular dental arch was achieved with the same protocol as used in the maxillary arch. After a 1 -month period, both archwires were replaced by $0.017 \times 0.025$-in nickel-titanium wires. The final $0.019 \times 0.025$-in stainless steel archwires were placed, and dental occlusal adjustments were performed during 9 months. The total active orthodontic treatment period was approximately 12 months, including the surgical time.

\section{TREATMENT RESULTS}

The 7-month postsurgical intraoral photographs showed improvement of the occlusion with a significant $\mathrm{AOB}$ reduction (Fig 6). According to the patient's report, the headaches and TMJ pain decreased significantly after the TMJ surgery. The lateral and panoramic radiographs after a 13.5-month period showed the presence of bilateral Mitek anchors. In this patient, 2 anchors were used on the left side to have better bone support after less than satisfactory stability after placement of the first anchor. Considerable bone remodeling was observed on the right condyle; third molar absence and the corrected AOB were also noticeable (Fig 7). The cephalometric evaluation (Table) and tracing superposition (Fig 8) before 


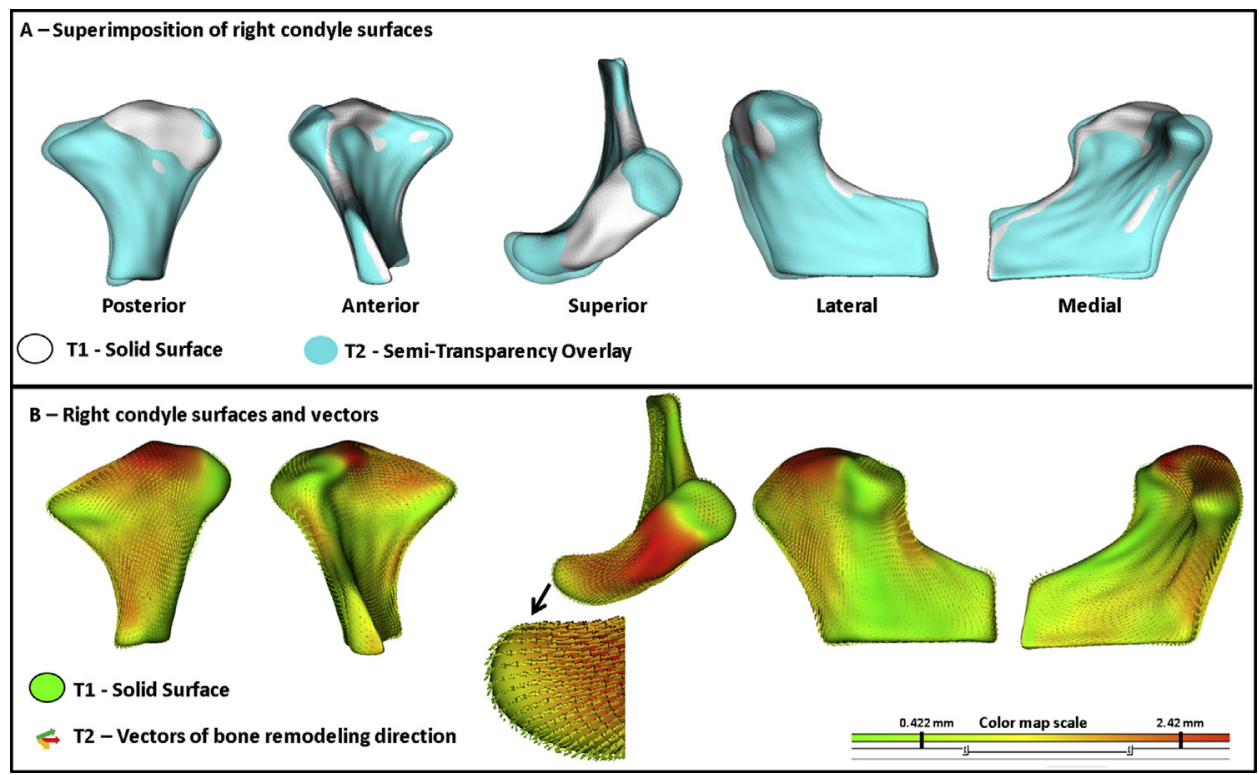

Fig 9. Right condyle regional superimposition: $\mathbf{A}$, pretreatment and 1-year posttreatment images showing severe bone remodeling; $\mathbf{B}$, color map with quantitative assessment and directions of bone remodeling.

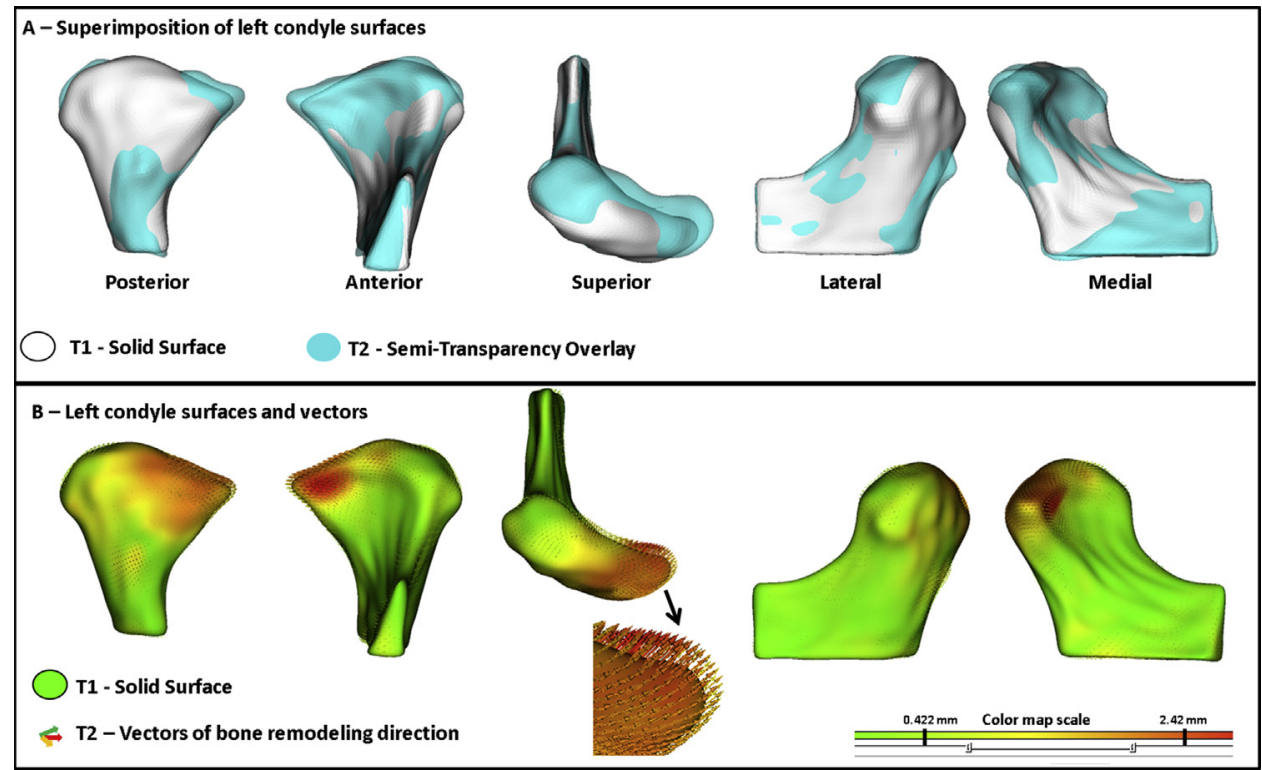

Fig 10. Left condyle regional superimposition: A, pretreatment and 1-year posttreatment showing mild condylar remodeling; B, color map with quantitative assessment and directions of bone remodeling.

and after treatment showed a slight counterclockwise rotation of the mandibular plane (MP to SN). In addition, the same method of 3D model acquisition using 3D Slicer (SPHARM-PMD) and ITK-SNAP software during pretreatment was used for the 1-year posttreatment analysis. ${ }^{15,16}$ Through a local voxel-based registration $^{33}$ between 3D models using the same anatomic region (first third of the ramus below the 


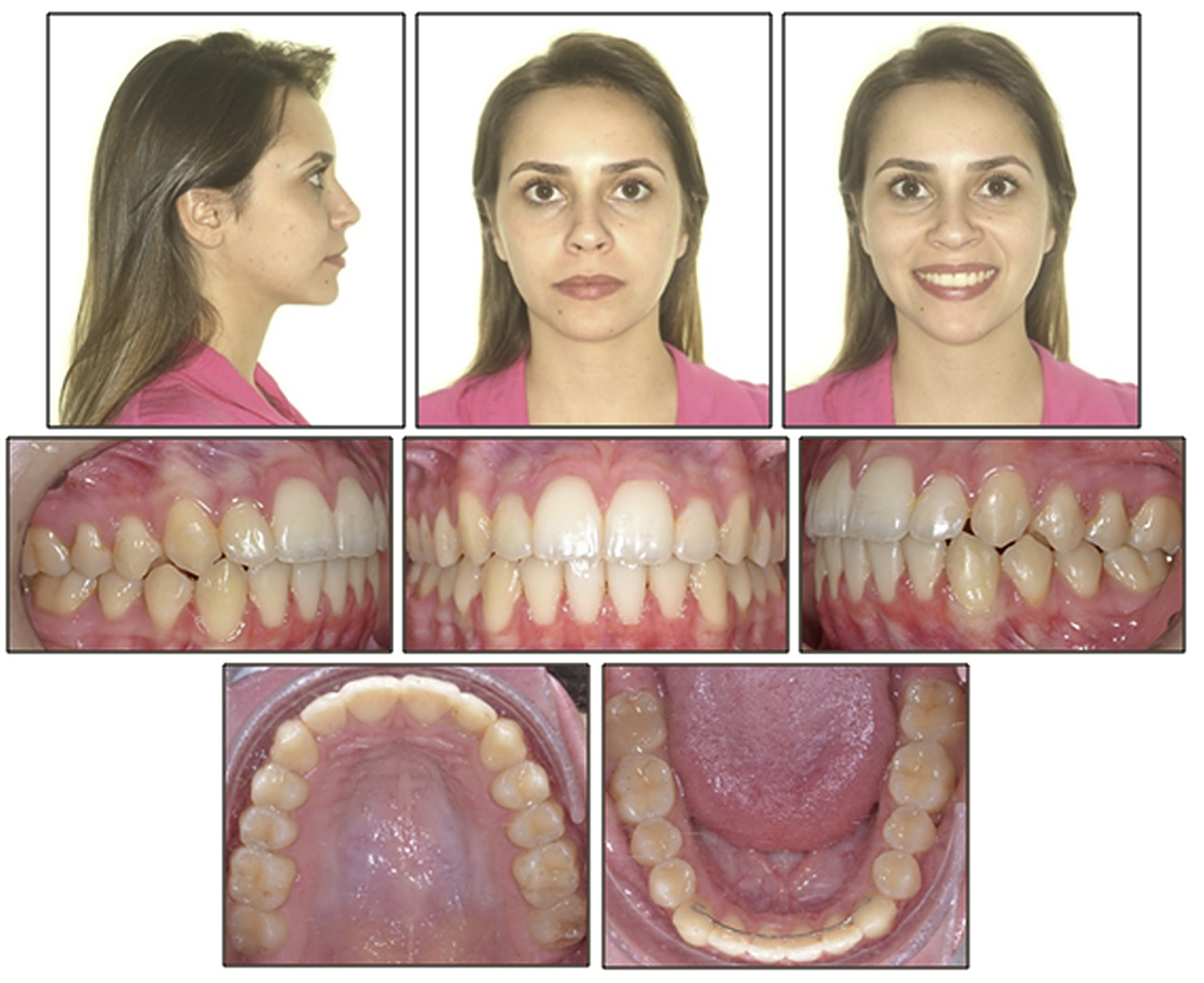

Fig 11. Extraoral and intraoral photographs at follow-up up 11 months after surgery (immediately after orthodontic treatment).

mandibular notch), the models were superimposed, and a color map with vectors of bone remodeling directions was obtained, presented in Figures 9 and 10. The individual shape and morphology of the condyles at posttreatment can be best seen in the online Supplementary Material (available at www.ajodo.org). Furthermore, the long-term stability is shown in Figure 11, which represents the final orthodontic treatment, and Figure 12 shows the 2-year follow-up.

\section{DISCUSSION}

A patient diagnosed with an $A O B$ malocclusion and bilateral TMJ osteoarthritis was treated with articular disc repositioning and fixed orthodontics. The excessive mandibular stress on the condyles overloading the TMJ is a possible mechanism for the TMJ disorder; in most cases, reports of $\mathrm{AOB}$ acquired phenomenon have occurred because of the collapse of the mandibular condyles. $^{7,11,34}$ The relationship between internal derangement of the TMJ and $\mathrm{AOB}$ was studied by Byun et al. ${ }^{14} \mathrm{~A}$ positive correlation was found between dentofacial morphology and internal derangements, such as a more posteriorly rotated ramus, and a tendency toward a skeletal Class 11 pattern, when compared with those having normal disc positions.

Chen et $\mathrm{al}^{35}$ showed, according to their MRl findings, that all of the acquired open-bite patients had anteriorly displaced discs, and most had experienced TMJ clicking (85\%) and limited opening (62\%). They concluded that these condylar morphologic changes suggested osteoarthritis secondary to internal derangement. Findings suggest that the improvement of clockwise rotation of the 

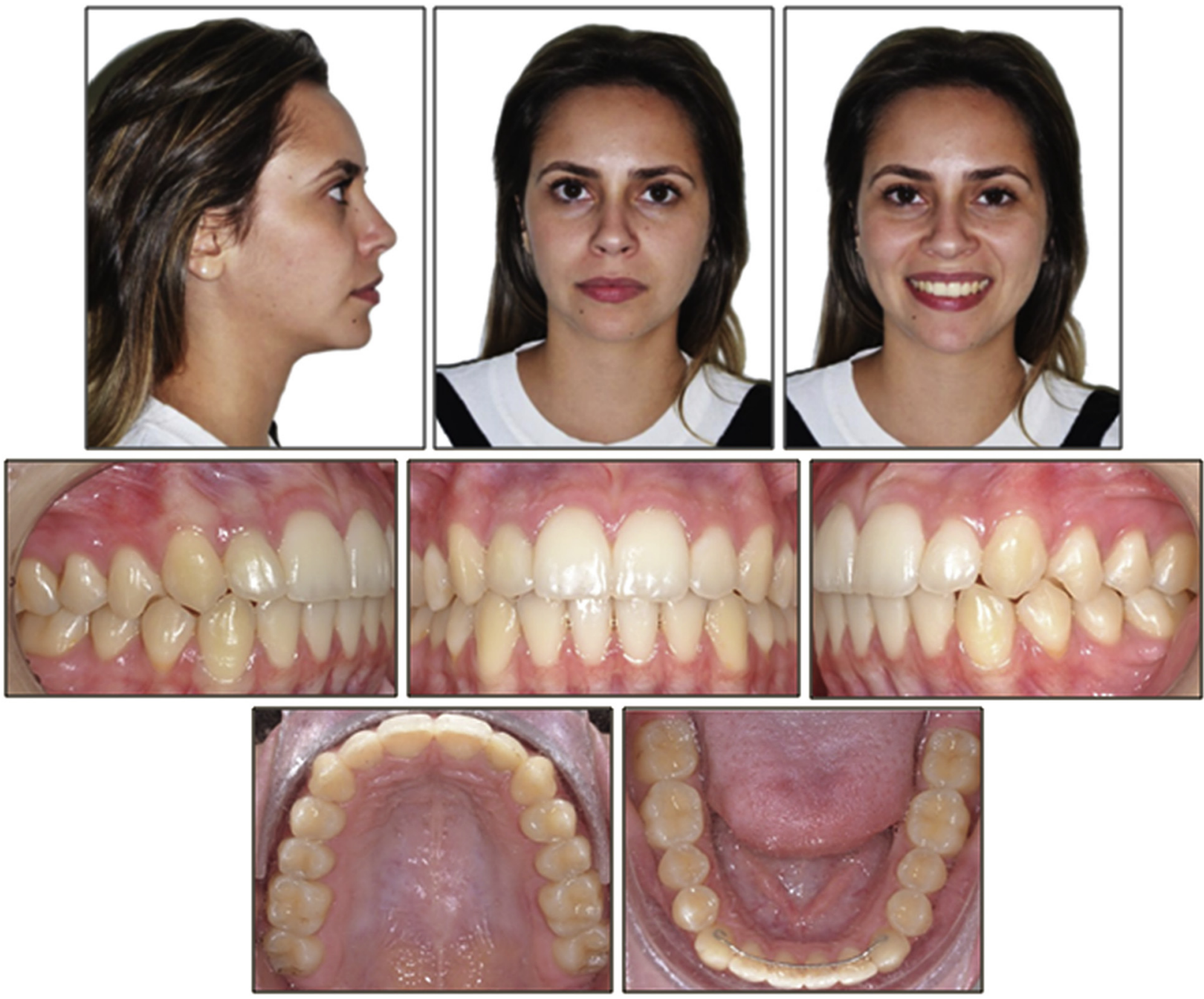

Fig 12. Extraoral and intraoral photographs 2 years after surgery (longest follow-up).

mandible, reducing the overloading of the TMJs, can be indispensable for the treatment of acquired open bite associated with TMJ osteoarthritis. ${ }^{36}$ Despite its unpredictable course, the ideal position of the condyle and a stable occlusion can attain a balanced biomechanical joint, inhibiting the progression of osteoarthritis and possibly causing functional and adaptive remodeling of the condyles. ${ }^{37}$

The use of 3D models from CBCT allowed a better understanding of the morphologic bone remodeling of the condyles after the disc repositioning surgery. This kind of analysis was well demonstrated by Porciuncula et $\mathrm{al}^{38}$ who stated "monitoring of condylar changes with 3-dimensional surface modeling and quantification from CBCT offered additional information to guide the orthodontics in regard to appropriate timing for deboning and mechanics while allowing accomplishment of acceptable skeletal and dental outcomes."

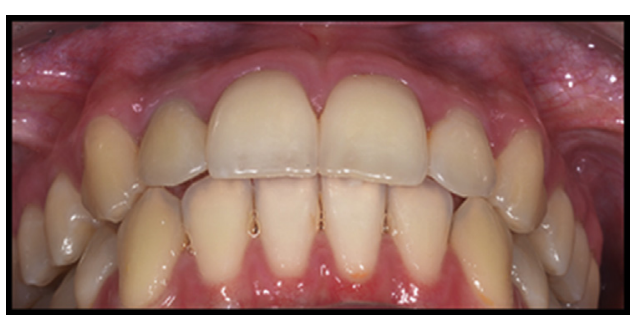

Fig 13. Posttreatment occlusal relationship (longest follow-up).

The TMJ articular disc repositioning surgery leads the condyle to a more inferior position inside the articular fossa, creating a slight counterclockwise rotation of the mandibular plane, consequently decreasing the $\mathrm{AOB}$ and improving the intercuspation of the posterior teeth. ${ }^{39}$ 


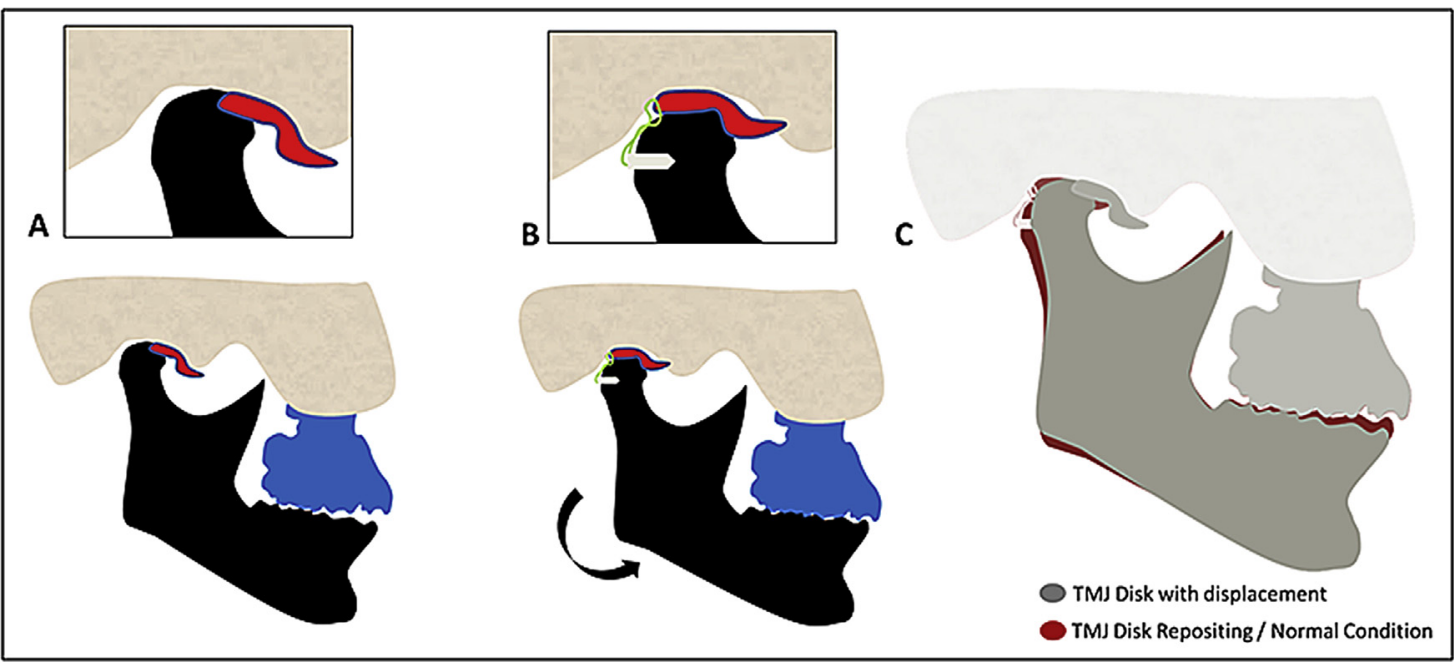

Fig 14. A, Schematic figure of TMJ articular disc anterior displacement; B, after articular disc repositioning; $\mathbf{C}$, schematic representation of pretreatment and posttreatment superimposition.

In this case report, the short period of orthodontic treatment and the absence of significant alterations in dental position with great changes in the relationship between the mandibular and maxillary arches (Table; Fig 13) support the hypothesis illustrated in Figure 14.

\section{CONCLUSIONS}

A patient with AOB, bilateral TMJ osteoarthritis, TMJ pain, and headaches was successfully treated with fixed orthodontics and TMJ disc repositioning. The entire treatment lasted 12 months. The TMJ disc repositioning surgery created space within the joint to accommodate the articular disc and promoted a slight counterclockwise rotation of the mandible that allowed adequate occlusion and stability. The 2-year follow-up showed occlusal stability and significant decreases in TMJ pain, headaches, and functional limitation.

\section{SUPPLEMENTARY DATA}

Supplementary data related to this article can be found online at http://dx.doi.org/10.1016/j.ajodo. 2016.09.032.

\section{REFERENCES}

1. Cozza P, Mucedero M, Baccetti T, Franchi L. Early orthodontic treatment of skeletal open-bite malocclusion: a systematic review. Angle Orthod 2005;75:707-13.

2. Wanjau J, Sethusa MP. Etiology and pathogenesis of anterior open bite: a review. East Afr Med J 2010;87:452-5.

3. Lentini-Oliveira DA, Carvalho FR, Rodrigues CG, Ye Q, Prado LB, Prado GF, et al. Orthodontic and orthopaedic treatment for anterior open bite in children. Cochrane Database Syst Rev 2014;(9): CD005515.
4. Cozza P, Baccetti T, Franchi L, Mucedero M, Polimeni A. Sucking habits and facial hyperdivergency as risk factors for anterior open bite in the mixed dentition. Am J Orthod Dentofacial Orthop 2005; 128:517-9.

5. Ngan P, Fields HW. Open bite: a review of etiology and management. Pediatr Dent 1997;19:91-8.

6. Garrett J, Araujo E, Baker C. Open-bite treatment with vertical control and tongue reeducation. Am J Orthod Dentofacial Orthop 2016;149:269-76.

7. Okeson JP. Evolution of occlusion and temporomandibular disorder in orthodontics: Past, present, and future. Am J Orthod Dentofacial Orthop 2015;147(Suppl 5):S216-23.

8. Arnett GW, Milam SB, Gottesman L. Progressive mandibular retrusion-idiopathic condylar resorption. Part 1.Am J Orthod Dentofacial Orthop 1996;110:8-15.

9. Wolford LM. Can orthodontic relapse be blamed on the temporomandibular joint? J Orthod Sci 2014;3:95-105.

10. Okeson JP. Temporomandibular disorders: etiology and classification. In: Kandasamy S, Greene SC, Rinchuse JD, Stockstill WJ, editors. TMD and orthodontics: a clinical guide for the orthodontist. New York: Springer International Publishing; 2015. p. 19-36.

11. Poveda Roda R, Bagan JV, Díaz Fernández JM, Hernández Bazán S, Jiménez Soriano Y. Review of temporomandibular joint pathology. Part 1: classification, epidemiology and risk factors. Med Oral Patol Oral Cir Bucal 2007;12:292-8.

12. Schellhas KP, Piper MA, Omlie MR. Facial skeleton remodeling due to temporomandibular joint degeneration: an imaging study of 100 patients. Cranio 1992;10:248-59.

13. Melo CE, Oliveira JL, Jesus AC, Maia ML, de Santana JC, Andrade $\mathrm{LB}$, et al. Temporomandibular disorders dysfunction in headache patients. Med Oral Patol Oral Cir Bucal 2012;17:e1042-6.

14. Byun ES, Ahn SJ, Kim TW. Relationship between internal derangement of the temporomandibular joint and dentofacial morphology in women with anterior open bite. Am J Orthod Dentofacial Orthop 2005;128:87-95.

15. Cevidanes LH, Hajati AK, Paniagua B, Lim PF, Walker DG, Palconet G, et al. Quantification of condylar resorption in temporomandibular joint osteoarthritis. Oral Surg Oral Med Oral Pathol Oral Radiol Endod 2010;110:110-7. 
16. Yushkevich PA, Piven J, Hazlett HC, Smith RG, He S, Gee JC, et al. User-guided 3D active contour segmentation of anatomical structures: significantly improved efficiency and reliability. Neuroimage 2006;31:1116-28.

17. Greenlee GM, Huang GJ, Chen SS, Chen J, Koepsell T, Hujoel P. Stability of treatment for anterior open-bite malocclusion: A meta-analysis. Am J Orthod Dentofacial Orthop 2011;139:154-69.

18. Lin LH, Huang GW, Chen CS. Etiology and treatment modalities of anterior open bite malocclusion. J Exp Clin Med 2013;5:1-4.

19. Kim YH, Han UK, Lim DD, Serraon ML. Stability of anterior openbite correction with multiloop edgewise archwire therapy: a cephalometric follow-up study. Am J Orthod Dentofacial Orthop 2000; 118:43-54.

20. Heimer MV, Tornisiello Katz CR, Rosenblatt A. Non-nutritive sucking habits, dental malocclusions, and facial morphology in Brazilian children: a longitudinal study. Eur J Orthod 2008;30:580-5.

21. Nahoum H1, Horowitz SL, Benedicto EA. Varieties of anterior open-bite. Am J Orthod 1972;61:486-92.

22. Wilkes $\mathrm{CH}$. Internal derangements of the temporomandibular joint. Pathological variations. Arch Otolaryngol Head Neck Surg 1989;115:469-77.

23. Seligman DA, Pullinger AG. The role of intercuspal occlusal relationships in temporomandibular disorders: a review. J Craniomandib Disord 1991;5:96106.

24. Pullinger AG, Seligman DA, Gornbein JA. A multiple logistic regression analysis of the risk and relative odds of temporomandibular disorders as a function of common occlusal features. J Dent Res 1993;72:96879.

25. Kau CH, Bejemir MP. Application of virtual three-dimensional surgery planning in management of open bite with idiopathic condylar resorption. Ann Maxillofac Surg 2015;249-54.

26. Dimitroulis G. Temporomandibular disorders: a clinical update. BMJ 1998;317:190-4.

27. McNeill C. Temporomandibular disorders: guidelines for classification, assessment, and managment. 2nd ed. Chicago: Quintessence Books; 1993.

28. Paik CH, Woo YJ, Boyd RL. Treatment of an adult patient with vertical maxillary excess using miniscrew fixation. J Clin Orthod 2003; 37:423-8.

29. Baek MS, Choi YJ, Yu HS, Lee KJ, Kwak J, Park YC. Long-term stability of anterior open-bite treatment by intrusion of maxillary posterior teeth. Am J Orthod Dentofacial Orthop 2010;138: 396.e1-9: discussion, 396-8.
30. Kuroda S, Sugawara Y, Tamamura N, Takano-Yamamoto T. Anterior open bite with temporomandibular disorder treated with titanium screw anchorage: evaluation of morphological and functional improvement. Am J Orthod Dentofacial Orthop 2007;131:550-60.

31. Sugawara J, Baik UB, Umemori M, Takahashi 1, Nagasaka H, Kawamura $\mathrm{H}$, et al. Treatment and posttreatment dentoalveolar changes following intrusion of mandibular molars with application of a skeletal anchorage system (SAS) for open bite correction. lnt J Adult Orthod Orthognath Surg 2002;17:243-53.

32. Mercuri LG. Alloplastic temporomandibular joint replacement: rationale for the use of custom devices. Int J Oral Maxillofac Surg 2012;41:1033-40.

33. Alhadidi A, Cevidanes LH, Paniagua B, Cook R, Festy F, Tyndall D. 3D quantification of mandibular asymmetry using the SPHARM-PDM tool box. Int J Comput Assist Radiol Surg 2012;7:265-71.

34. Ooi K, Yura S, Inoue N, Totsuka Y. Factors related to the incidence of anterior disc displacement without reduction and bony changes of the temporomandibular joint in patients with anterior open bite. Oral Maxillofac Surg 2014;18:397-401.

35. Chen YJ, Shih TT, Wang JS, Wang HY, Shiau YY. Magnetic resonance images of the temporomandibular joints of patients with acquired open bite. Oral Surg Oral Med Oral Pathol Oral Radiol Endod 2005;99:734-42.

36. Tanaka E, Yamano E, Inubushi T, Kuroda S. Management of acquired open bite associated with temporomandibular joint osteoarthritis using miniscrew anchorage. Korean J Orthod 2012;42: 144-54.

37. Tanaka E, Kikuchi K, Sasaki A, Tanne K. An adult case of TMJ osteoarthrosis treated with splint therapy and the subsequent orthodontic occlusal reconstruction: adaptive change of the condyle during the treatment. Am J Orthod Dentofacial Orthop 2000; 118:566-71.

38. Porciúncula GM, Koerich L, Eidson L, Gandini Junior LG, Gonçalves JR. Can cone-beam computed tomography superimposition help orthodontists better understand relapse in surgical patients? Am J Orthod Dentofacial Orthop 2014;146: 641-54.

39. Goncalves JR, Wolford LM, Cassano DS, da Porciuncula G, Paniagua B, Cevidanes LH. Temporomandibular joint condylar changes following maxillomandibular advancement and articular disc repositioning. J Oral Maxillofac Surg 2013;71: 1759.e1-15. 